Proceedings

\title{
Associations of Outdoor Activity, Screen Time with Body weight: A Cross-sectional Study of Chinese Preschool Chil- dren $^{\dagger}$
}

\author{
Weibing Ye ${ }^{1}$, Junfei Zhang ${ }^{2}$, Guoneng $X u^{1, *}$ and Shen Ma ${ }^{3, *}$ \\ 1 College of Physical Education and Health Sciences, Zhejiang Normal University, Jinhua 321004, Zhejiang, \\ China; ywbls@zjnu.cn \\ 2 Suzhou No.2 High School, Suzhou 234000, Anhui, China; zjf950628@126.com \\ 3 Physical Education Department, Zhejiang University of Water Resources and Electric Power, Hangzhou \\ 310018,Zhejiang, China; \\ * Correspondence: xgn@zjnu.cn(G.X.); Tel.: +86-138-0678-9221(G.X.). mashen@zjweu.edu.cn(G.X.), \\ 13396819246(S.M.)
}

\begin{abstract}
This study conducted to explore the relationship between outdoor activity time, screen time and body weight of children. All participants, 3-6 years of age $(n=1422)$, from 4 kindergartens in Hangzhou City, Zhejiang Province, were selected as the subjects by random cluster sampling. Weight and height were measured. Total screen time, time of outdoor play were self-reported by parents in a questionnaire. We used $\mathrm{X}^{2}$ test, $\mathrm{t}$-test and logistic regression analysis to analyze the data. After adjusting the influencing factors such as children's age, father's education level and screen time, the risk of overweight and obesity was 1.734 times (95\% CI: 1.178-2.552) for children with outdoor activity time $\leq 2 \mathrm{~h} / \mathrm{d}$, among which 2.050 times (95\% CI: 1.252-3.357) for boys, 1.472 times (95\% CI: 0.785-2.761) for girls. After adjusting the influencing factors such as children's age, father's education level and outdoor activity time, the risk of overweight and obesity in children whose screen time $\geq 1 \mathrm{~h} / \mathrm{d}$ was 1.639 times (95\% CI: 1.272-2.113) that in children whose screen time was less than $1 \mathrm{~h} / \mathrm{d}$, including 1.474 times (95\% CI: 1.057-2.057) for boys, and 1.676 times (95\% CI: $1.119-2.511)$ for girls. Thus, both long screen time and outdoor activity time were associated with the increases the risk of overweight and obesity.
\end{abstract}

Keywords: preschool; children; obesity; screen time; outdoor activity time

Publisher's Note: MDPI stays neutral with regard to jurisdictional claims in published maps and institutional affiliations.

\section{(c) (i)}

Copyright: $\odot 2021$ by the authors. Submitted for possible open access publication under the terms and conditions of the Creative Commons Attribution (CC BY) license (http://creativecommons.org/licenses/by/4.0/).

\section{Introduction}

Child obesity has become one of the most challenging public health problems, and this issue is no longer a patent of developed countries. Many developing countries are also at risk of the increasing prevalence of childhood obesity.

With the popularization of electronic media products such as televisions, computers, and mobile phones, the opportunities for children to access electronic products continue to increase. Watching TV, playing with computers, and using mobile phones have become an indispensable part of children's lives. However, watching TV, computers, mobile phones and other screen devices for a long time has a great impact on childhood obesity[1]. However, the superimposed effects of screen time and outdoor activities on childhood overweight and obesity still lack corresponding research[2].

\section{Materials and Methods}

This study adopted a random cluster sampling method and selected all 3-6 year-old children from 4 kindergartens in Hangzhou, a city in eastern China as the research subject. A total of 1,422 children were tested, including 716 boys and 706 girls. The average age was $4.48 \pm 0.91$ years. The age of the research subjects is half-year-old as a group, divided 
into 7 groups, 3 years old means 3-3.4 years old; 3.5 years old means 3.5-3.9 years old; 4 years old means $4-4.4$ years old; 4.5 years old means $4.5-4.9$ years old; 5 years old means 5-5.4 years old; 5.5 years old means 5.5-5.9 years old; 6 years old means 6-6.5 years old.

We adopted a questionnaire survey method. From April to June 2019, after the children's afternoon school was over, the team members who received uniform training gathered the caregivers of the children surveyed in the classroom, and the team members and parents explained this time. For the purpose and requirements of the survey, parents should fill out the questionnaire on a voluntary basis after being informed. When filling in the questionnaire, the relevant personnel of the survey will explain the questionnaire filling requirements. After the explanation, the parents independently complete the questionnaire filling work. In this process, the relevant personnel will be investigated. Answer the doubts of parents in the process of filling in the questionnaire in time. After the completion of the filling, the relevant personnel of the survey will collect the questionnaires on the spot to ensure that there are no missing items.

The questionnaire of this research adopts the content of "The Fifth National Fitness Monitoring Work Plan (Kindergarten Part)". The investigated family factors related to children's overweight and obesity include: whether the child participates in special sports training courses, the reproductive age of the parents, the education level of the parents, the parents' occupation, whether the parents have exercise habits and the child caregivers. The education level is divided into 3 levels: junior high school and below, high school (including technical secondary school), university (including junior college and above); child caregivers are divided into parents, elderly at home, and others (relatives, nanny, etc.)

The outdoor activity time in this study requires parents to carefully recall the average daily outdoor activity time in the past week when children were at home. According to the children's physical activity guide, the average daily outdoor activity time is divided into "> $2 \mathrm{~h} "$ and " $\leq 2 \mathrm{~h} "[3]$.

The screen time in this study is to ask parents to recall the average daily time of children watching TV, mobile phones, tablets, computers, video games, etc. in the past week, and according to the World Health Organization and China's recommendations for children's daily screen time not exceeding 1 hour The standard divides the average daily screen time into " < 1h" and " $\geq 1 \mathrm{~h} "[2]$.

\section{Results}

\subsection{Physical characteristics of children}

Table 1. Subjects' height and body weight and there gender differences $(M \pm S D)$.

\begin{tabular}{ccccccc}
\hline age & boys & height & \multicolumn{3}{c}{ body weight } \\
girls & boys & $p$ \\
\hline 3 & $98.78 \pm 4.13$ & girls & $p 7.73 \pm 3.57$ & 0.09 & $15.66 \pm 1.85$ & $15.15 \pm 1.91$ \\
3.5 & $102.59 \pm 4.69$ & $100.24 \pm 4.36$ & 0.00 & $16.46 \pm 2.19$ & $15.50 \pm 2.22$ \\
4 & $106.01 \pm 4.60$ & $104.49 \pm 4.19$ & 0.01 & $18.05 \pm 3.45$ & $16.70 \pm 2.07$ & 0.092 \\
4.5 & $108.95 \pm 4.08$ & $107.99 \pm 4.18$ & 0.06 & $19.40 \pm 2.94$ & $18.20 \pm 2.61$ & 0.001 \\
5 & $112.69 \pm 4.51$ & $111.16 \pm 4.17$ & 0.01 & $20.25 \pm 3.12$ & $19.03 \pm 2.56$ \\
5.5 & $116.47 \pm 4.25$ & $115.20 \pm 4.54$ & 0.03 & $22.02 \pm 3.71$ & $20.61 \pm 2.69$ \\
6 & $116.77 \pm 4.38$ & $115.34 \pm 4.43$ & 0.00 & $22.18 \pm 3.35$ & $20.62 \pm 3.15$ \\
total & $109.04 \pm 7.33$ & $107.94 \pm 7.32$ & 0.00 & $19.18 \pm 3.74$ & 0.001 & 0.002 \\
\end{tabular}

Table 2. Subjects' BMI and its' gender differences $(\mathrm{M} \pm \mathrm{SD})$.

\begin{tabular}{cccc}
\hline age & boys & girls & $p$ \\
\hline 3 & $16.03 \pm 1.43$ & $15.83 \pm 1.38$ & 0.359 \\
3.5 & $15.59 \pm 1.37$ & $15.38 \pm 1.68$ & 0.308 \\
4 & $15.96 \pm 2.05$ & $15.27 \pm 1.43$ & 0.005 \\
\hline
\end{tabular}




\begin{tabular}{cll}
\hline 4.5 & $16.29 \pm 1.88$ & $15.57 \pm 1.68$ \\
5 & $15.89 \pm 1.76$ & $15.38 \pm 1.48$ \\
5.5 & $16.15 \pm 1.85$ & $15.52 \pm 1.74$ \\
6 & $16.23 \pm 1.98$ & $15.26 \pm 1.77$ \\
total & $16.02 \pm 1.79$ & $15.46 \pm 1.59$ \\
\hline
\end{tabular}

Table 3. Report rates of overweight and obesity in children of different gender groups ( $n, \%)$.

\begin{tabular}{ccccc}
\hline gender & Normal weight & Overweight and obesity & $\mathbf{X}^{2}$ & $p$ \\
\hline boys & $498(69.6)$ & $218(30.4)$ & \multirow{2}{*}{35.490} & \multirow{2}{*}{0.000} \\
girls & $586(83.0)$ & $120(17.0)$ & & \\
\hline
\end{tabular}

\subsection{Outdoor activity time and children's overweight and obesity}

Table 4. Comparison the weight grouping under different outdoor activity time groups ( $\mathrm{n}, \%)$.

\begin{tabular}{|c|c|c|c|c|}
\hline group & Normal weight & Overweight and obesity & $\mathrm{X}^{2}$ & $p$ \\
\hline \multicolumn{5}{|l|}{ boys } \\
\hline outdoor activity time $<2 \mathrm{~h} / \mathrm{d}$ & $402(67.7)$ & $187(32.3)$ & 5.795 & 0.016 \\
\hline $\begin{array}{l}\text { outdoor activity time } \geq 2 \mathrm{~h} / \mathrm{d} \\
\text { girls }\end{array}$ & $96(78.7)$ & $26(21.3)$ & & \\
\hline outdoor activity time $<2 \mathrm{~h} / \mathrm{d}$ & $504(82.5)$ & $107(17.5)$ & 0.854 & 0.335 \\
\hline $\begin{array}{l}\text { outdoor activity time } \geq 2 \mathrm{~h} / \mathrm{d} \\
\text { total }\end{array}$ & $82(86.3)$ & $13(13.7)$ & & \\
\hline outdoor activity time $<2 \mathrm{~h} / \mathrm{d}$ & $906(75.2)$ & $299(24.8)$ & 4.749 & 0.029 \\
\hline outdoor activity time $\geq 2 \mathrm{~h} / \mathrm{d}$ & $178(82.0)$ & $39(18.0)$ & & \\
\hline
\end{tabular}

Table 5. Logistic regression of the relationship between outdoor activity time and overweight and obesity.

\begin{tabular}{ccc}
\hline Independent variable & Unadjusted OR (95\%CI) & adjusted OR (95\%CI) \\
\hline $\begin{array}{c}\text { boys } \\
\text { outdoor activity time } \geq 2 \mathrm{~h} / \mathrm{d} \\
\text { outdoor activity time }<2 \mathrm{~h} / \mathrm{d} \\
\text { girls }\end{array}$ & 1 & 1 \\
$\begin{array}{c}\text { outdoor activity time } \geq 2 \mathrm{~h} / \mathrm{d} \\
\text { outdoor activity time }<2 \mathrm{~h} / \mathrm{d} \\
\text { total }\end{array}$ & $1.763(1.106-2.811) *$ & $2.050(1.252-3.357) *$ \\
$\begin{array}{c}\text { outdoor activity time } \geq 2 \mathrm{~h} / \mathrm{d} \\
\text { outdoor activity time }<2 \mathrm{~h} / \mathrm{d}\end{array}$ & 1 & 1 \\
& $1.339(0.720-2.492)$ & $1.472(0.785-2.761)$ \\
$* P<0.05$, Adjusted factors include: children's age, father's education level, screen time & $1.734(1.178-2.552) *$
\end{tabular}

\subsection{Screen time and children's overweight and obesity}

Table 6. Comparison the weight grouping under different screen time groups ( $\mathrm{n}, \%)$.

\begin{tabular}{|c|c|c|c|c|}
\hline group & Normal weight & Overweight and obesity & $\mathrm{X}^{2}$ & $p$ \\
\hline \multicolumn{5}{|l|}{ boys } \\
\hline screen time $<1 \mathrm{~h} / \mathrm{d}$ & $278(73.9)$ & $98(26.1)$ & 7.183 & 0.007 \\
\hline $\begin{array}{l}\text { screen time } \geq 1 \mathrm{~h} / \mathrm{d} \\
\text { girls }\end{array}$ & $220(64.7)$ & $120(35.3)$ & & \\
\hline screen time $<1 \mathrm{~h} / \mathrm{d}$ & $368(85.6)$ & $62(14.4)$ & 5.184 & 0.023 \\
\hline $\begin{array}{l}\text { screen time } \geq 1 \mathrm{~h} / \mathrm{d} \\
\text { total }\end{array}$ & $218(79.0)$ & $58(21.0)$ & & \\
\hline screen time $<1 \mathrm{~h} / \mathrm{d}$ & $646(80.1)$ & $160(19.1)$ & 15.765 & 0.000 \\
\hline screen time $\geq 1 \mathrm{~h} / \mathrm{d}$ & $438(71.1)$ & $178(28.9)$ & & \\
\hline
\end{tabular}


Table 7. Logistic regression of the relationship between screen time and overweight and obesity.

\begin{tabular}{ccc}
\hline Independent variable & Unadjusted OR (95\%CI) & adjusted OR $(\mathbf{9 5} \% \mathbf{C I})$ \\
\hline boys & 1 & 1 \\
screen time $<1 \mathrm{~h} / \mathrm{d}$ & $1.547(1.123-2.131) *$ & $1.474(1.057-2.057) *$ \\
screen time $\geq 1 \mathrm{~h} / \mathrm{d}$ & & 1 \\
girls & 1 & $1.676(1.119-2.511) *$ \\
screen time $<1 \mathrm{~h} / \mathrm{d}$ & $1.579(1.064-2.345) *$ & 1 \\
screen time $\geq 1 \mathrm{~h} / \mathrm{d}$ & & $1.639(1.272-2.113) *$ \\
total & 1 & \\
screen time $<1 \mathrm{~h} / \mathrm{d}$ & $1.641(1.284-2.098) *$ & \\
screen time $\geq 1 \mathrm{~h} / \mathrm{d}$ & & \\
\hline
\end{tabular}

${ }^{*} \mathrm{P}<0.05$, Adjusted factors include: children's age, father's education level, outdoor activity time

\section{Discuss}

Studies have shown that the occurrence of myopia is related to the decrease in outdoor activities and the increase in TV, computer and mobile phone time[4]. This study shows that outdoor activity time and screen time increase the risk of overweight and obesity in 3-6 year-old children. Relevant studies have found that parental education has a certain influence on childhood obesity. It is believed that the incidence of obesity in children with mothers with low education is more common than that of mothers with high education.[5] This study found that mother's education level has no effect on childhood obesity, but father's education level has a more important impact on childhood obesity. Related mechanisms need to be further investigated. Therefore, when we studying the OR value of screen time and outdoor activity time on the incidence of overweight and obesity in children, we adjusted the impact of father's education and age(table 5 and table 7).

We must consider the impact of lockdown measures instituted during the COVID-19 pandemic on childhood obesity and myopia.

Author Contributions: Conceptualization, W.Y.; methodology, S.M.; writing - review and editing, J.Z.; supervision, W.Y.; project administration, G.X.; funding acquisition, S.M. All authors have read and agreed to the published version of the manuscript.

Funding: : This study was supported by the grant (18YJA890017) from Humanities and Social Science Research Fund Project of China Education Ministry. The authors are thankful to Zhejiang Normal University for the support.

Conflicts of Interest: The authors declare no conflict of interest.

\section{References}

1. Fang $\mathrm{K}, \mathrm{Mu} \mathrm{M}$, Liu K, et al. Screen time and childhood overweight/obesity: A systematic review and meta-analysis[J]. Child: care, health and development. 2019, 45(5): 744-753.

2. World Health Organization. Guidelines on physical activity, sedentary behaviour and sleep for children under 5 years of age: web annex: evidence profiles[R]. World Health Organization, 2019.

3. Lipnowski S, Leblanc C M, Society C P, et al. Healthy active living: Physical activity guidelines for children and adolescents[J] Paediatrics \& child health. 2012, 17(4): 209-210.

4. Alvarez-Peregrina C, Sánchez-Tena M Á, Martinez-Perez C, et al. The relationship between screen and outdoor time with rates of myopia in Spanish children[J]. Frontiers in Public Health. 2020, 8: 596.

5. Spinelli A, Buoncristiano M, Kovacs V A, et al. Prevalence of severe obesity among primary school children in 21 European countries[J]. Obesity facts. 2019, 12(2): 244-258. 